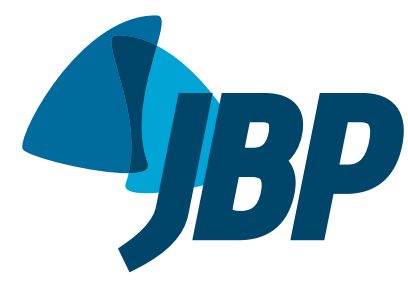

\title{
Lipoabdominoplasty: repercussions for diaphragmatic mobility and lung function in healthy women
}

Sandra Fluhr ${ }^{1, a}$, Armèle Dornelas de Andrade1, 1 , Emanuel José Baptista Oliveira ${ }^{2, c}$ Taciano Rocha ${ }^{1, \mathrm{~d}}$, Ana Irene Carlos Medeiros ${ }^{1, \mathrm{e}}$, Amanda Couto ${ }^{1, \mathrm{f}}$, Juliana Netto Maia ${ }^{1, \mathrm{~s}}$, Daniella Cunha Brandão,

1. Departamento de Fisioterapia, Universidade Federal de Pernambuco, Recife (PE) Brasil.

2. Departamento de Cirurgia Plástica, Hospital Agamenon Magalhães, Recife (PE) Brasil.

a. iD http://orcid.org/0000-0002-8261-0894

b. iD http://orcid.org/0000-0001-9430-4395

c. (iD http://orcid.org/0000-0002-9369-3883

d. (iD http://orcid.org/0000-0001-6190-1425

e. (iD) http://orcid.org/0000-0003-2958-6079

f. (iD) http://orcid.org/0000-0002-7927-9192

g. iD $h t t p: / / o r c i d . o r g / 0000-0001-8680-180 X$

h. (iD) http://orcid.org/0000-0001-8805-6815

Submitted: 29 May 2018

Accepted: 12 August 2018

Study carried out in the Departamento de Fisioterapia, Universidade Federal de Pernambuco, Recife (PE) Brasil.

\begin{abstract}
Objective: To evaluate the impact of lipoabdominoplasty on diaphragmatic mobility (DM) and lung function in healthy women. Methods: This was a prospective cohort study using high-resolution ultrasound and forced spirometry to assess DM and lung function, respectively, prior to lipoabdominoplasty, as well as on postoperative day (POD) 10 and POD 30. DM was measured under two conditions: during tidal volume breathing and during a VC maneuver. Results: The sample consisted of 20 women, with a mean age of $39.85 \pm 7.52$ years and a mean body mass index of $26.21 \pm 2.0 \mathrm{~kg} / \mathrm{m}^{2}$. Comparing the preoperative and postoperative periods, we found that DM and lung function values were significantly lower after lipoabdominoplasty, the mean DM on POD 10 being 17\% and $15 \%$ lower during tidal volume breathing and during the VC maneuver, respectively, in comparison with the preoperative mean ( $p=0.009$ and $p<0.001$, respectively). In addition, FEV, FVC, and PEF were significantly lower on POD 10 than in the preoperative period ( $p=0.046, p=0.002$, and $p<0.001$, respectively), returning to preoperative values by POD 30. Conclusions: Lipoabdominoplasty appears to have negative shortterm repercussions for DM and lung function in healthy women. However, lung function and DM are both apparently restored to preoperative conditions by POD 30

(ClinicalTrials.gov identifier: NCT02762526 [http://www.clinicaltrials.gov/])

Keywords: Abdominoplasty; Lipectomy; Ultrasonography; Diaphragm/physiology; Diaphragm/physiopathology; Lung/physiology; Lung/physiopathology; Respiratory mechanics; Spirometry; Respiratory function tests.
\end{abstract}

\section{INTRODUCTION}

Plastic surgery techniques for contouring the abdomen, such as lipoabdominoplasty, are among the most often requested procedures, ranking third among plastic surgery techniques performed worldwide.(1-4) Lipoabdominoplasty, which combines classical abdominoplasty and liposuction, results in a significant reduction in the fat pad and has the added benefits of muscle plication and the removal of skin tissue. ${ }^{(5)}$ It has become common practice among plastic surgeons and has a low incidence of postoperative complications if the clinical condition of the patient is evaluated prior to the procedure. ${ }^{(5,6)}$ However, there have been reports of respiratory comorbidities, including respiratory failure, atelectasis, pneumonia, and bronchospasm, in the postoperative period after lipoabdominoplasty. ${ }^{(7-11)}$ Such complications might be attributable to increased intra-abdominal pressure (IAP), caused by plication of the aponeurosis of the rectus abdominis muscle, which could lead to changes in diaphragmatic mobility (DM) ${ }^{(12)}$ as well as impaired lung function. ${ }^{(10,13)}$ In some of the cases reported, lung function was reduced to half of that observed prior to surgery. Although none of the authors of those reports evaluated DM in the affected patients, other factors have been implicated in a postoperative decrease in lung volumes, such as the administration of anesthetic drugs, visceral manipulation, the incision in the abdominal wall, and patient fear of injury from the surgery. $(6,14)$ Pain exerts an effect on the postoperative evolution of patients submitted to abdominal surgery, with a negative impact on lung function. ${ }^{(15)}$

The primary objective of this study was to identify respiratory complications in healthy women undergoing lipoabdominoplasty. To that end, we evaluated DM and lung function at several time points.

\section{METHODS}

\section{Study design and participants}

This was a prospective cohort study conducted in the Physical Therapy Sector of the Laboratory of Physiology

\section{Correspondence to:}

Sandra Fluhr. Departamento de Fisioterapia, Universidade Federal de Pernambuco, Avenida Jornalista Anibal Fernandes, s/n, Cidade Universitária, CEP 50670 901, Recife, PE, Brasil.

Tel.: 5581 3049-3633. E-mail: sandrafluhr@hotmail.com

Financial support: This study received financial support from the Conselho Nacional de Desenvolvimento Cientifico e Tecnológico (CNPq, National Council for Scientific and Technological Development; Grant no 432865/2016-0), Fundação de Amparo à Ciência e Tecnologia do Estado de Pernambuco (FACEPE, Foundation for the Support of Scientific and Technological Development in the State of Pernambuco; APO 0154-4.08/15), Coordenação de Aperfeiçoamento de Pessoal de Nivel Superior (CAPES, Office for the Advancement of Higher Education; Finance Code 001), and Programa Nacional de Cooperação Acadêmica (PROCAD, Brazilian Academic Cooperation Program; Grant no 88881068409/2014-01). 
and Cardiopulmonary Physiotherapy and at the Plastic Surgery Clinic of the Hospital das Clínicas da Universidade Federal de Pernambuco (HC-UFPE, Federal University of Pernambuco Hospital das Clínicas), as well as at the Plastic Surgery Clinic of the Hospital Agamenon Magalhães, between July of 2015 and March of 2016. The study was approved by the Human Research Ethics Committee of the HC-UFPE Health Sciences Center (CAAE protocol no. 15225913.0.0000.5208) and was registered with ClinicalTrials.gov (identifier: NCT02762526). We employed a non-probability sampling process, in which we screened all individuals who met the eligibility criteria.

\section{Eligibility criteria}

We included women between 25 and 55 years of age who underwent lipoabdominoplasty with plication of the rectus abdominis muscle. All had type IV or $\mathrm{V}$ abdominal deformity, as described by Bozola. ${ }^{(16)}$ We selected women with no history of respiratory or cardiac comorbidities. We also selected only women with a body mass index $\leq 30 \mathrm{~kg} / \mathrm{m}^{2}$ and a minimum score of 18 on the Mini-Mental State Examination.

We excluded women who were current smokers or had a smoking history greater than 10 pack-years. Women with an $\mathrm{FEV}_{1}<80 \%$ of the predicted value or an $\mathrm{FEV}_{1} / \mathrm{FVC}$ ratio $<70 \%$ of the predicted value were also excluded.

\section{Surgical procedure}

For the surgical procedure, all patients were sedated and received spinal or epidural anesthesia. First, the surgical site was marked. A solution of epinephrine (diluted 1:250,000 in saline) was then infiltrated into the abdominal cavity to initiate liposuction. The aspiration began through the supra-umbilical region, continuing along the sides and through the infra-umbilical region. After the liposuction, the navel was isolated and only the infra-umbilical skin was resected, as in classic abdominoplasty. ${ }^{(5)}$

Umbilicoplasty was performed by attaching the deep dermis of the navel to the aponeurosis of the rectus abdominis muscle, after which the deep dermis of the neo-umbilicus was attached to the flap with monocryl 3-0 sutures at the intercardinal points. The skin flap was fixed in two planes, with mononylon 3-0 sutures in the subcutaneous tissue and monocryl 5-0 sutures in the dermis, initially with separate single sutures and subsequently with continuous sutures. At the intercardinal and cardinal points of the navel, respectively, we used the modified Allgöwer-Donati suture and single sutures, both with mononylon 4-0 sutures. ${ }^{(17)}$

\section{Outcome measures}

All of the outcomes investigated were measured at three time points: in the preoperative period, on postoperative day (POD) 10, and on POD 30. Initially, medical histories were taken and all of the patients underwent a physical examination. Personal data were collected, and we recorded anthropometric measurements-weight (in $\mathrm{kg}$ ), height (in $\mathrm{m}$ ), and body mass index (in $\mathrm{kg} / \mathrm{m}^{2}$ ) -as well as vital signs-HR, $\mathrm{SpO}_{2}, \mathrm{RR}$, and blood pressure. Patients were asked to remain seated with their arms resting on their legs and to remain quiet during the measurement of vital signs.

\section{$D M$}

We used a high-resolution ultrasound system (SonoAce R3; Samsung Medison, Seoul, South Korea) with a convex $3.5 \mathrm{MHz}$ transducer. The protocol used was that suggested by Testa et al. ${ }^{(12,18)}$ The patients received a verbal command to breathe evenly for the measurement of DM during tidal volume $\left(\mathrm{V}_{\mathrm{T}}\right)$ breathing and then to perform VC maneuvers (Figure 1), during which each curve relating to the displacement of the dome of the diaphragm (in $\mathrm{mm}$ ) was measured immediately after acquisition of the images. The maneuvers were repeated in order to obtain five satisfactory images. We considered the average of the three highest values that were within $10 \%$ of each other.

\section{Lung function}

We used a portable spirometer (Microloop MK8; Micro Medical, Kent, England) in order to evaluate FVC, $\mathrm{FEV}_{1}$, FEF between $25 \%$ and $75 \%$ of the FVC $\left(\mathrm{FEF}_{25-75 \%}\right), \mathrm{PEF}$, and the $\mathrm{FEV}_{1} / \mathrm{FVC}$ ratio. The maneuvers were carried out in accordance with the recommendations of the American Thoracic Society ${ }^{(19)}$ and other guidelines for pulmonary function testing. ${ }^{(20)}$

\section{Dyspnea}

Patients were asked about their perception of dyspnea at rest and during the procedures performed. We applied the modified Borg Scale, in accordance with the American Thoracic Society recommendations. ${ }^{(19)}$

\section{Pain}

We used a visual analog scale (21) $^{(2)}$ sisting of a one-dimensional instrument for graduation of pain intensity level. Pain was assessed at rest during each respiratory evaluation. To avoid measurement bias, all procedures were performed by the same examiner during all phases of the study.

\section{Statistical analysis}

The sample size was calculated, on the basis of the results of a pilot study involving 10 patients, with the G*Power3 software package. (22) The calculation was performed by determining the mean difference between the preoperative and POD 10 values $(\Delta 1)$, as well as between the preoperative and POD 30 values $(\Delta 2)$ for the most clinically relevant variables: $F_{1}, F_{1}$ FVC, and DM. For $\mathrm{FEV}_{1}$, we observed a $\Delta 1$ value of $13.4 \pm$ 5 and a $\Delta 2$ value of $3.5 \pm 3$. For FVC, we observed a $\Delta 1$ value of $11.8 \pm 2.62$ and a $\Delta 2$ value of $4.7 \pm 4.5$. For DM, we observed a $\Delta 1$ value of $18 \pm 7.16$ and a $\Delta 2$ value of $2.62 \pm 3.13$. Therefore, we required 5 patients for $\mathrm{FEV}_{1}, 7$ patients for FVC, and 7 patients for DM, which would give all of those variables a power 

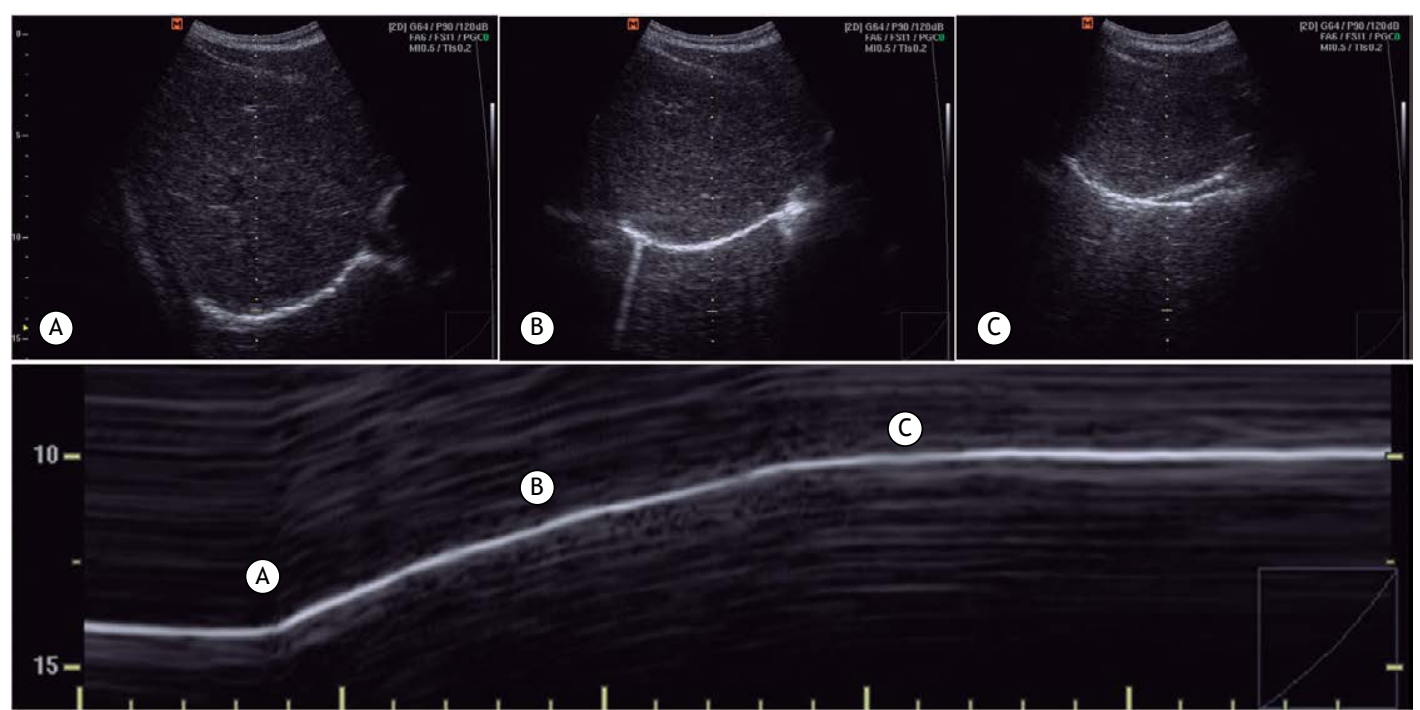

Figure 1. Assessment of diaphragmatic mobility by M-mode ultrasound, with the placement of markers for determining diaphragm displacement during the VC maneuver. A, B, and C indicate the beginning, middle, and end of the inspiratory cycle, respectively.

of $95 \%$ and an alpha of 0.05 . However, we decided to select 27 patients, considering the potential for losses to follow-up in prospective cohort studies.

The data were analyzed with SigmaPlot software for Windows, version 12.0 (Systat Software, San Jose, CA, USA). To characterize the sample, we calculated descriptive statistics, using means \pm standard deviations, means ( $95 \%$ CIs), or medians (interquartile ranges) for quantitative variables.

The Shapiro-Wilk test and Levene's test for homogeneity of variance were applied in order to verify the normality and homogeneity of the data, respectively. For comparisons among time points, we used two-way repeated-measures ANOVA with the Holm-Sidak post hoc test to compare means for quantitative variables with normal, homogeneous distribution. For quantitative variables with a non-normal distribution, we used Friedman's repeated-measures ANOVA on ranks, followed by Tukey's post hoc test for variables that presented a statistical difference. The effect size was determined by calculating the Cohen's $d$, which involved obtaining the mean difference between the time points and dividing the result by the pooled standard deviation. ${ }^{(23)}$ Pearson's correlation coefficient was used in order to detect associations between DM variables and lung function variables. Statistical analyses were performed with the IBM SPSS Statistics software package, version 20.0 (IBM Corporation, Armonk, NY, USA). Values of $p<0.05$ were considered statistically significant.

\section{RESULTS}

The initial sample comprised 27 women, all of whom underwent lipoabdominoplasty. However, only 20 of those women completed the protocol (Figure 2). Anthropometric variables, clinical characteristics, and vital signs are summarized in Table 1 . Two patients were excluded from the analysis of DM, because of technical problems related to the ultrasound examination. On POD 10, DM was relatively low, during $\mathrm{V}_{\mathrm{T}}$ breathing and at TLC-9.54 mm (8.42-10.99 mm) and $51.23 \mathrm{~mm}$ (41.66-55.89 mm), respectively-those values returning to normal by POD $30-12.37 \mathrm{~mm}(10.49-14.13 \mathrm{~mm})$ and $63.35 \mathrm{~mm}(55.19-68.34 \mathrm{~mm})$, respectively-at which point they were comparable to those obtained in the preoperative period- $11.56 \mathrm{~mm}(9.65-13.48 \mathrm{~mm})$ and $60.15 \mathrm{~mm}$ (51.95-67.84 $\mathrm{mm})$, respectively. As can be seen in Figure 3, the differences between the preoperative and postoperative values were significant for the images acquired during $\mathrm{V}_{T}$ breathing ( $\mathrm{p}=$ 0.009), as well as for those acquired during the VC maneuver $(p<0.001)$.

Lung function parameters at the three time points evaluated are shown in Table 2 . There were significant differences among the time points for $\mathrm{FEV}_{1}$, FVC, and PEF, all of which were lower on POD 10 than in the preoperative period and were restored to normal values by POD 30. The $\mathrm{FEV}_{1} / \mathrm{FVC}$ ratio and $\mathrm{FEF}_{25-75 \%}$ remained unchanged after lipoabdominoplasty, with no statistical differences between any of the time points. On POD 10, the DM measured during the VC maneuver correlated positively, albeit moderately, with $\mathrm{FEV}_{1}(r$ $=0.502 ; p=0.034)$ and PEF $(r=0.515 ; p=0.029)$, as depicted in Figure 4.

Of the 20 women evaluated, 7 reported pain on POD 10. Three of those women classified their pain as mild and 4 classified it as moderate. One of the women reported moderate pain on POD 30. Two women reported perceived dyspnea on POD 10, the dyspnea being classified as not very intense in one case and very intense in the other. On POD 30, none of the patients reported dyspnea. No differences were observed between the pain/dyspnea reported at rest and that reported during the execution of the maneuvers, in terms of the perception or intensity of 


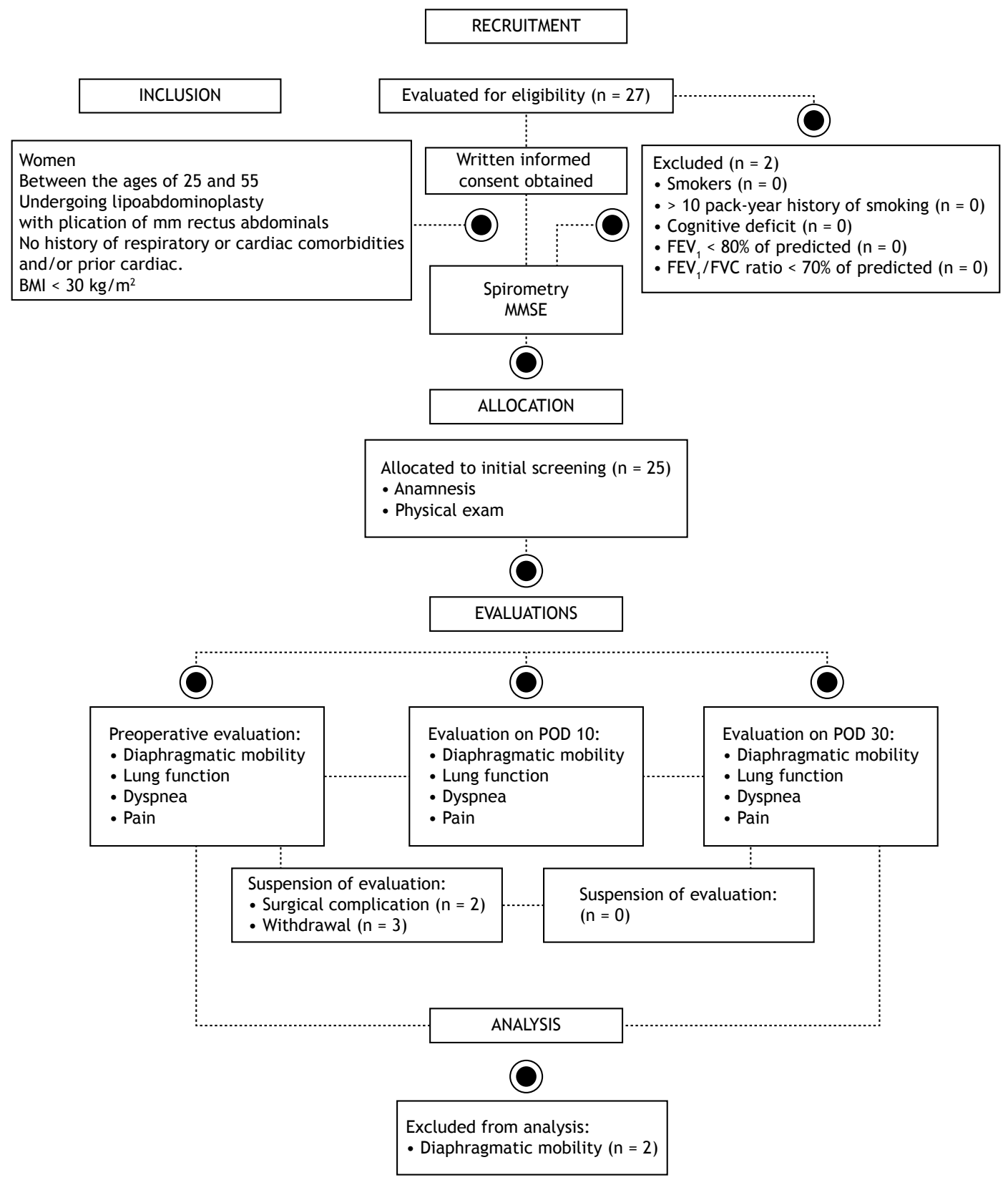

Figure 2. Flowchart of the study design. BMI: body mass index; MMSE: Mini-Mental State Examination; and POD: postoperative day.

pain or in terms of the perception of dyspnea, at any of the time points evaluated.

\section{DISCUSSION}

The main findings of our study are that lipoabdominoplasty with plication of the rectus abdominis muscle promoted a reduction in DM and worsening of lung function in healthy women, as evaluated on POD 10. However, both of those parameters showed a tendency to return to preoperative values by POD 30.

In comparison with the preoperative means, the mean DM on POD 10 was $17 \%$ lower when measured during $\mathrm{V}_{\mathrm{T}}$ breathing and $15 \%$ lower when measured during the VC maneuver. By POD 30, the DM had returned to values comparable to those obtained in the preoperative period. However, there is a shortage of studies evaluating DM in this specific population, which precludes any comparisons with our findings.

We hypothesize that there were two main causes of the behavior of DM in our sample. The first potential cause was the influence of plication of the rectus abdominis muscle near the xiphoid process, and the second was the increase in IAP.

Regarding the influence of plication of the rectus abdominis muscle, we suggest that approximation of 
the edges of the rectus abdominis muscles can generate a higher tensile strength in the fibers of those muscles, reducing the anteroposterior and transverse diameter of the chest, which will in turn reduce DM, because of the anatomical proximity between the upper insertions of the rectus abdominis muscles and one of the origins of the diaphragm muscle. The rectus abdominis muscle attaches to the fifth, sixth, and seventh costal cartilages and to the xiphoid process, whereas the costal portion of the diaphragm also originates from the last six ribs. In addition, the trunk flexion posture adopted by the patient for just over 10 days after the procedure can increase the magnitude of the changes. ${ }^{(24,25)}$

The primary action of the transversus abdominis and abdominal oblique muscles is to pull the abdominal wall inward, increasing the IAP. In doing so, they induce cranial displacement of the diaphragm, leading to an increase in pleural pressure and a consequent reduction in lung volume. Although the rectus abdominis muscle must do the same when the ventral abdominal wall has an outward convexity, we would expect that when the convexity is inward, an isolated muscle contraction would pull the wall slightly outward. (26) In an animal study, De Troyer et al.(27) analyzed the selective activation of the rectus abdominis muscle by electrical stimulation, finding that the ribcage and sternum were

Table 1. Anthropometric variables, clinical characteristics, and vital signs. ${ }^{\text {a }}$

\begin{tabular}{|c|c|}
\hline Variable & $(n=20)$ \\
\hline Age (years) & $39.85 \pm 7.52$ \\
\hline Weight (kg) & $67.48 \pm 6$ \\
\hline Height (m) & $1.60 \pm 0.07$ \\
\hline $\mathrm{BMI}\left(\mathrm{kg} / \mathrm{m}^{2}\right)$ & $26.21 \pm 2$ \\
\hline MMSE score & $29.8 \pm 0.41$ \\
\hline RR (breaths/min) & $17 \pm 3.42$ \\
\hline HR (bpm) & $69 \pm 9.54$ \\
\hline $\mathrm{SpO}_{2}(\%)$ & $98.3 \pm 1.34$ \\
\hline
\end{tabular}

BMI: body mass index; and MMSE: Mini-Mental State Examination. ${ }^{a}$ Values expressed as mean \pm SD.

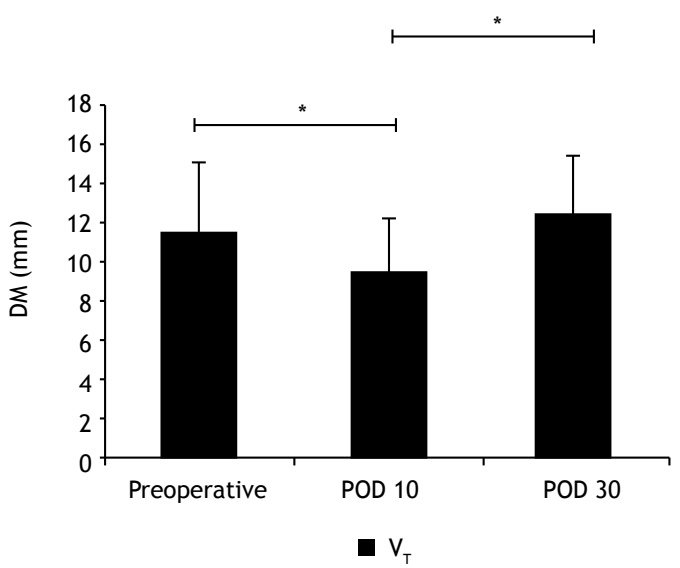

displaced in caudal and anteroposterior directions, whereas the transverse diameters of the lower ribcage were decreased. Therefore, the plication of the rectus abdominis muscle causes an increase in IAP and pleural pressure, regardless of the shape of the abdominal wall. Despite the limitations of comparison, these findings corroborate the hypothesis put forth in our study: that plication of the aponeurosis generates tension and thus limits thoracic expansion. We hypothesize that the reduction in DM can also be explained by the postoperative increase in IAP, which persisted at least until POD 10, caused by the plication of the rectus abdominis muscle to correct diastasis recti, which prevents the diaphragm from descending. ${ }^{(26)}$ After plication, the abdominal region can properly assist in the lung expansion and IAP values remain within the normal range, which in healthy adults is up to 5 $\mathrm{mmHg}$. Pressures above $15 \mathrm{mmHg}$ can cause further damage to the respiratory system. ${ }^{(28,29)}$ Although our study does not present the IAP values of the women who underwent lipoabdominoplasty, other authors have described the behavior of IAP after similar surgical procedures. Talisman et al. ${ }^{(30)}$ measured IAP oscillations during abdominoplasty in 18 patients and studied the relevance of such oscillations for patient evolution in the immediate postoperative period. Three patients who underwent plication to correct diastasis recti presented an IAP above $24 \mathrm{cmH}_{2} \mathrm{O}$ in the immediate postoperative period and above $20 \mathrm{cmH}_{2} \mathrm{O}$ on POD 1. The authors concluded that such patients are at a higher risk of developing respiratory distress in the immediate postoperative period.

Plication of the rectus abdominis muscle near the xiphoid process and the consequent increase in IAP would place the diaphragm at a mechanical disadvantage, resulting in restrictive lung disease in patients undergoing this type of surgery. In our patient sample, we observed a postoperative decrease in spirometric parameters, the lower values persisting at least until POD 10.

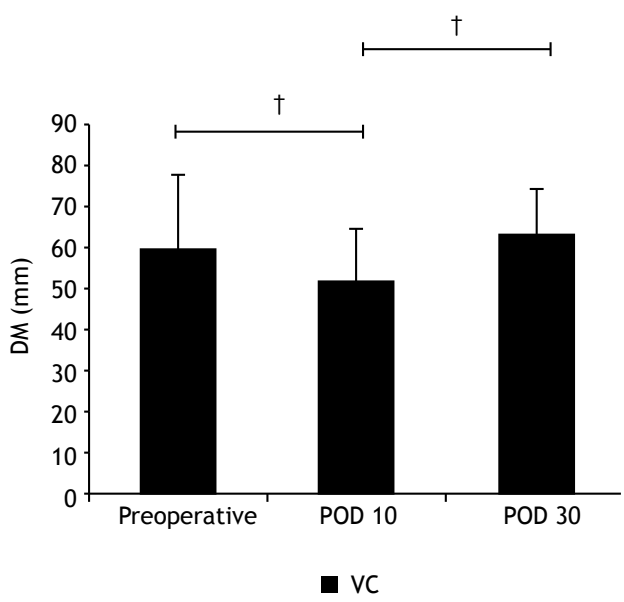

Figure 3. Diaphragmatic mobility (DM), measured during tidal volume breathing $\left(\mathrm{V}_{T}\right)$ and during a $\mathrm{VC}$ maneuver $(\mathrm{VC})$, at the three time points evaluated. Values of $\mathrm{p}$ were calculated with two-way repeated-measures ANOVA followed by the Holm-Sidak post hoc test. POD: postoperative day. ${ }^{*} p=0.009$ vs. Preoperative. ${ }^{\dagger} p<0.001$ vs. Preoperative. 
Table 2. Lung function at the three time points evaluated. ${ }^{a}$

\begin{tabular}{|c|c|c|c|c|c|c|c|}
\hline \multirow[t]{3}{*}{ Variable $^{b}$} & \multirow{3}{*}{$\begin{array}{c}\text { Preop. } \\
\text { (n = 20) } \\
\text { Value }\end{array}$} & \multicolumn{2}{|c|}{$\begin{array}{l}\text { POD } 10 \\
(n=20)\end{array}$} & \multicolumn{3}{|c|}{$\begin{array}{l}\text { POD } 30 \\
(n=20)\end{array}$} & \multirow[t]{3}{*}{ p* } \\
\hline & & Value & Cohen's d & Value & \multicolumn{2}{|c|}{ Cohen's d } & \\
\hline & & & $\begin{array}{l}\text { (Preop. vs. } \\
\text { POD 10) }\end{array}$ & & $\begin{array}{l}\text { (Preop. vs. } \\
\text { POD 30) }\end{array}$ & $\begin{array}{l}\text { (POD } 10 \text { vs. } \\
\text { POD } 30 \text { ) }\end{array}$ & \\
\hline $\mathrm{FEV}_{1} / \mathrm{FVC}$ & $\begin{array}{c}101.75 \\
(98.25-105.25)\end{array}$ & $\begin{array}{c}98.65 \\
(94.8-102.5)\end{array}$ & 0.4 & $\begin{array}{c}102.07 \\
(94.38-104.77)\end{array}$ & 0.05 & 0.51 & 0.209 \\
\hline $\mathrm{FEV}_{1}^{\dagger}$ & $\begin{array}{c}89.5 \\
(84.2-95.0)\end{array}$ & $\begin{array}{c}83.0 \\
(69.0-91.0)\end{array}$ & 0.55 & $\begin{array}{c}87.5 \\
(81.2-94.2)\end{array}$ & 0.23 & 0.35 & $0.046^{\ddagger}$ \\
\hline FVC & $\begin{array}{c}90.65 \\
(86.49-94.81)\end{array}$ & $\begin{array}{c}82.25 \\
(76.04-88.46)\end{array}$ & 0.74 & $\begin{array}{c}85.14 \\
(78.6-91.68)\end{array}$ & 0.50 & 0.23 & $0.002^{\ddagger}$ \\
\hline $\mathrm{FEF}_{25-75 \%}$ & $\begin{array}{c}99.65 \\
(90.08-109.22)\end{array}$ & $\begin{array}{c}86.05 \\
(73.12-98.98)\end{array}$ & 0.55 & $\begin{array}{c}99.21 \\
(90.08-108.35)\end{array}$ & 0.02 & 0.61 & 0.064 \\
\hline PEF & $\begin{array}{c}73.60 \\
(67.66-79.54)\end{array}$ & $\begin{array}{c}57.95 \\
(49.84-66.06)\end{array}$ & 1.03 & $\begin{array}{c}71.71 \\
(65.24-78.19)\end{array}$ & 0.15 & 1.07 & $<0.001^{\ddagger, \S}$ \\
\hline
\end{tabular}

Preop.: preoperative period; POD: postoperative day; and $\mathrm{FEF}_{25-75 \%}$ : FEF between $25 \%$ and $75 \%$ of the FVC. ${ }^{a}$ Values expressed as mean $(95 \% \mathrm{CI})$, except where otherwise indicated. ${ }^{\mathrm{b}} \mathrm{All}$ variables shown in percentages of the predicted values. *Two-way repeated-measures ANOVA with the Holm-Sidak post hoc test for variables with a normal, homogeneous distribution; Friedman's repeated-measures ANOVA on ranks with Tukey's post hoc test for variables with a non-normal distribution. ${ }^{\dagger}$ Median (interquartile range). ${ }^{~}$ Significant difference between the Preop. and POD 10 values. §Significant difference between the POD 10 and POD 30 values.
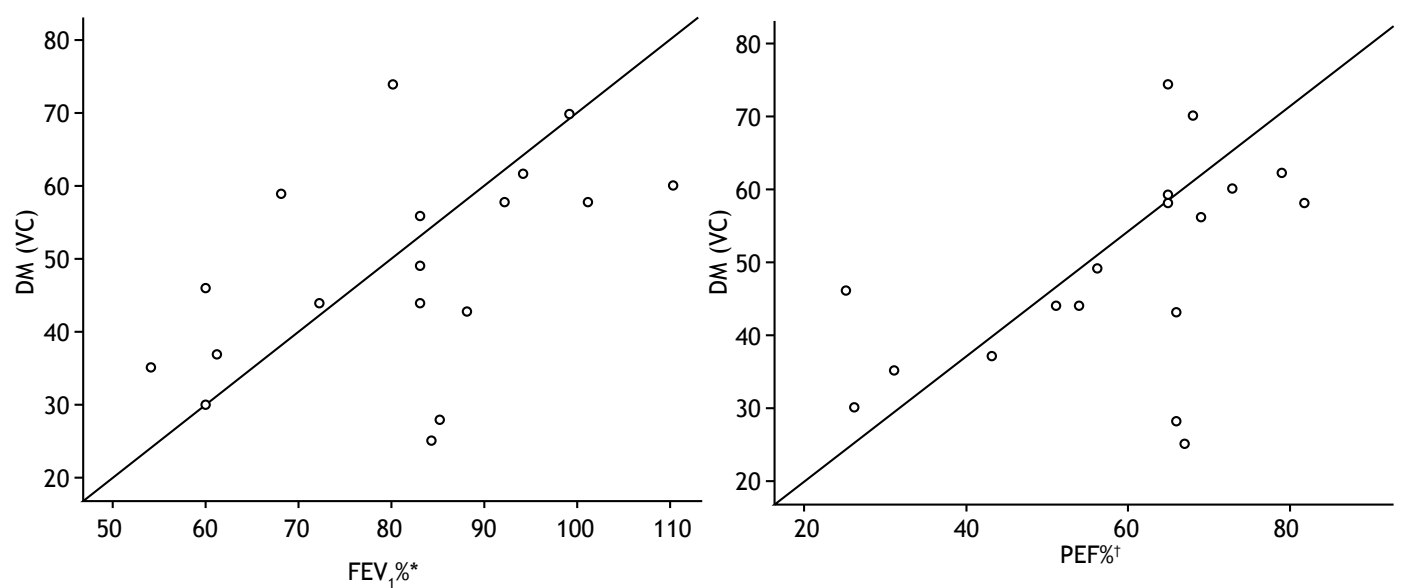

Figure 4. Diaphragmatic mobility (DM) during a VC maneuver on postoperative day 10, in comparison with the FEV and PEF values (both in \% of predicted) obtained at the same time point. Values of $\mathrm{p}$ were calculated with Pearson's correlation coefficient. *Significant correlation with DM during the VC maneuver $(r=0.502 ; p=0.034)$. ${ }^{\dagger}$ Significant correlation with DM during the VC maneuver $(r=0.515 ; p=0.029)$.

The spirometric data obtained in our study show that there was pronounced worsening of lung function on POD 10, as evidenced by lower FEV 1 and FVC values, and a near-total restoration of normal lung function by POD 30. Similarly, PEF was reduced on POD 10 and returned to preoperative values on POD 30 , the difference between POD 10 and POD 30 being significant. During the study period, there were no significant changes in $\mathrm{FEF}_{25-75 \%}$ or in the $\mathrm{FEV}_{1} / \mathrm{FVC}$ ratio. These data suggest that lipoabdominoplasty promotes the development of restrictive lung disease.

To our knowledge, there have been no previous studies evaluating lung function in women undergoing lipoabdominoplasty. However, other authors have studied the behavior of lung function in the postoperative period after abdominoplasty and have observed that lung function worsens in the immediate postoperative period and returns to preoperative levels by POD 30. . $^{(10,13,31,32)}$ Our choice to evaluate patients at that time point was based on those studies. Tercan et al. ${ }^{(10)}$ evaluated 14 healthy women who underwent abdominoplasty, observing a significant decline in FVC on POD 10 and subsequent improvement by POD 30, when FVC surpassed the preoperative values, suggesting that correction of diastasis recti abdominis promotes effective containment of the abdominal wall, improving the spirometric parameters over a period $>30$ days. Similarly, Helene Junior et al. ${ }^{(13)}$ found that, among patients undergoing abdominoplasty, the values of $\mathrm{FEV}_{1}, \mathrm{FVC}, \mathrm{FEF}_{25-75 \%}$, and PEF were lower on POD 4 than in the preoperative period, the $\mathrm{FEV}_{1} / \mathrm{FVC}$ ratio remaining constant, although $\mathrm{FEV}_{1}$ and $\mathrm{FVC}$ were both below normal, suggesting a restrictive pattern. The authors also found that FVC and PEF showed 
significant improvement from POD 4 to POD 15 , as well as from POD 15 to POD 30, although neither returned to the preoperative value. In one long-term study of 24 patients undergoing total abdominoplasty, Perin et al. ${ }^{(31)}$ evaluated spirometric parameters during the preoperative period and after a mean period of 28 months. The authors found no difference between those two time points in terms of the lung function of the patients. Rodrigues et al. ${ }^{\left({ }^{(32)}\right.}$ studied the respiratory function of patients who underwent plication of the aponeurosis of the external abdominal oblique muscle and correction of diastasis recti. Those authors observed a ventilatory pattern similar to what occurs in the postoperative period in patients undergoing only correction of diastasis recti, concluding that the use of an L-shaped plication, per se, does not increase IAP; that is, the plication is not responsible for the impairment of lung function after abdominoplasty. The authors attributed the significant postoperative increase in IAP to the use of a compression garment, citing that as the most detrimental factor.

In the present study, we found that, on POD 10, DM during the VC maneuver correlated with lung function. We looked for correlations at that time point because we believe that patients undergoing lipoabdominoplasty show the most limitations in the first 10 days after the procedure. In our patient sample, DM during the VC maneuver showed a moderate positive correlation with PEF and with FEV ${ }_{1}$, although DM during $\mathrm{V}_{\mathrm{T}}$ breathing did not correlate with any of the spirometric parameters. These data indicate that some of the limitations in lung function in these patients can be explained by the reduction in DM caused by plication, that reduction being more pronounced at maximum effort, given that the sample consisted of healthy women. It is likely that there would be a strong correlation between lung function and $D M$, including $D M$ during $V_{T}$ breathing, in a population with pre-existing comorbidities.

In our study, pain, as measured with a visual analog scale, was reported by $35 \%$ and $5 \%$ of the patients on POD 10 and POD 30, respectively. Although some studies have shown that postoperative pain can be related to reduced lung volumes, ${ }^{(33)}$ we found no correlation between pain and lung function. We also did not consider pain a relevant factor for diaphragmatic dysfunction, because the behavior of spirometric parameters and DM in the patients with pain was similar to that observed in those without. That might be due to the fact that only 7 women reported pain, probably because most of the patients received analgesic medications, as is common practice in the postoperative period. In addition, unlike what occurs during upper abdominal surgery, there is no disruption of muscle fibers during lipoabdominoplasty, which is an important distinction, because muscle injury is the main cause of postoperative pain. ${ }^{(34)}$

On POD 10, the patients in our sample showed reductions in DM and lung function. However, dyspnea was not an important clinical factor in our study, being reported by only $10 \%$ of the patients evaluated.

Our study has some limitations, such as the fact that we did not evaluate respiratory muscle strength or diaphragm thickness. There is therefore a need for further studies involving such analyses, which could better elucidate our findings.

\section{REFERENCES}

1. Santos NP Dos, Barnabé AS, Fornari JV, Ferraz RRN. Pain assessment in patients undergoing cosmetic or reconstructive plastic surgery [Article in Portuguese]. Rev Bras Cir Plast. 2012;27(2):190-4.

2. American Society of Plastic Surgeons [homepage on the Internet]. Arlington Heights (IL): the Society; c2008 [cited 2017 Nov 1]. Report of the 2007 statistics: National Clearinghouse of Plastic Surgery Statistics. Available from: www.plasticsurgery.org/

3. Rohrich RJ, Stuzin JM. Globalization of plastic surgery: the world of plastic and reconstructive surgery in Brazil. Plast Reconstr Surg. 2012;130(4):967-8. https://doi.org/10.1097/PRS.0b013e31826703b1

4. Nahas FX. A pragmatic way to treat abdominal deformities based on skin and subcutaneous excess. Aesthetic Plast Surg. 2001;25(5):36571. https://doi.org/10.1007/s00266-001-0025-7

5. Saldanha OR, Pinto EBS, Matos Jr WN, Lucon RL, Magalhães F, Bello EML, et al. Lipoabdominoplasty - Saldanha's Technique. Rev Bras Cir Plast. 2003;(2):37-46.

6. Assumpção GG. Mini-abdominoplasty associated with liposuction and lowering of the umbilical scar without pedicular detachment [Article in Portuguese]. Rev Bras Cir Plast. 2012;27(3):450-6. https:// doi.org/10.1590/S1983-51752012000300021

7. ROE BB. Prevention and treatment of respiratory complications in surgery. N Engl J Med. 1960;263:547-50. https://doi.org/10.1056/ NEJM196009152631106

8. Palmon SC, Kirsch JR, Depper JA, Toung TJ. The effect of the prone position on pulmonary mechanics is frame-dependent. Anesth Analg. 1998;87(5):1175-80.

9. Rezaiguia S, Jayr C. Prevention of respiratory complications after abdominal surgery [Article in French]. Ann Fr Anesth Reanim. 1996;15(5):623-46. https://doi.org/10.1016/0750-7658(96)82128-9

10. Tercan M, Bekerecioglu M, Dikensoy O, Kocoglu H, Atik B, Isik
D, et al. Effects of abdominoplasty on respiratory functions: a prospective study. Ann Plast Surg. 2002;49(6):617-20. https://doi. org/10.1097/00000637-200212000-00011

11. Pierri A, Munegato G, Carraro L, Zaccaria F, Tiso E, Zotti EF Hemodynamic alterations during massive incisional hernioplasty. J Am Coll Surg. 1995;181(4):299-302.

12. Yamaguti WP, Paulin E, Shibao S, Kodaira S, Chammas MC, Carvalho CR. Ultrasound evaluation of diaphragmatic mobility in different postures in healthy subjects. J Bras Pneumol. 2007;33(4):407-13. https://doi.org/10.1590/S1806-37132007000400009

13. Helene Junior A, Saad Junior R, Stirbulov R. Avaliação da função respiratória em indivíduos submetidos à abdominoplastia. Rev Col Bras Cir. 2006;33(1):45-50. https://doi.org/10.1590/S010069912006000100011

14. Grams ST, von Saltiél R, Mayer AF, Schivinski Cl, de S Nobre LF, Nóbrega IS, et al. Assessment of the reproducibility of the indirect ultrasound method of measuring diaphragm mobility. Clin Physio Funct Imaging. 2014;34(1):18-25. https://doi.org/10.1111/cpf.12058

15. Tonella RM, Araújo S, Silva AM. Transcutaneous electrical nerve stimulation in the relief of pain related to physical therapy after abdominal surgery [Article in Portuguese]. Rev Bras Anestesiol. 2006;56(6):630-42

16. Bozola AR. Abdominoplasty: same classification and a new treatment concept 20 years later. Aesthetic Plast Surg. 2010;34(2):181-92. https://doi.org/10.1007/s00266-009-9407-z

17. Pigossi N, Tariki JY, de Cássia H, Calonge F, de Andrade AC, Misawa HT, et al. Tactics in the umbilical approach in abdominoplasties [Article in Portuguese]. Rev Hosp Clin Fac Med Sao Paulo. 1991;46(3):145-7.

18. Testa A, Soldati G, Giannuzzi R, Berardi S, Portale G, Gentiloni Silveri N. Ultrasound M-mode assessment of diaphragmatic 
kinetics by anterior transverse scanning in healthy subjects. Ultrasound Med Biol. 2011;37(1):44-52. https://doi.org/10.1016/j. ultrasmedbio.2010.10.004

19. ATS Committee on Proficiency Standards for Clinical Pulmonary Function Laboratories. ATS statement: guidelines for the six-minute walk test. Am J Respir Crit Care Med. 2002;166(1):111-7. Erratum in: Am J Respir Crit Care Med. 2016;193(10):1185. https://doi. org/10.1164/ajrccm.166.1.at1102

20. Duarte AA, Pereira CA, Rodrigues SC. Validation of new brazilian predicted values for forced spirometry in caucasians and comparison with predicted values obtained using other reference equations. Bras Pneumol. 2007;33(5):527-35. https://doi.org/10.1590/S180637132007000500007

21. Price DD, McGrath $P A$, Rafii A, Buckingham $B$. The validation of visual analogue scales as ratio scale measures for chronic and experimental pain. Pain. 1983;17(1):45-56. https://doi.org/10.1016/03043959(83)90126-4

22. Faul F, Erdfelder E, Lang AG, Buchner A. G*Power 3: a flexible statistical power analysis program for the social, behavioral, and biomedical sciences. Behav Res Methods. 2007;39(2):175-91. https://doi.org/10.3758/BF03193146

23. Sullivan GM, Feinn R. Using Effect Size-or Why the $P$ Value Is Not Enough. J Grad Med Educ. 2012;4(3):279-82. https://doi.org/10.4300/ JGME-D-12-00156.1

24. De Troyer A, Estenne M. Functional anatomy of the respiratory muscles. Clin Chest Med. 1988;9(2):175-93.

25. Sieck GC. Diaphragm muscle: structural and functional organization. Clin Chest Med. 1988:9(2):195-210.

26. De Troyer A, Boriek AM. Mechanics of the respiratory muscles. Compr Physiol. 2011;1(3):1273-300. https://doi.org/10.1002/cphy c100009

27. De Troyer A, Sampson M, Sigrist S, Kelly S. How the abdominal muscles act on the rib cage. J Appl Physiol Respir Environ Exerc Physiol. 1983;54(2):465-9. https://doi.org/10.1152/ jappl.1983.54.2.465

28. Luckianow GM, Ellis M, Governale D, Kaplan LJ. Abdominal compartment syndrome: risk factors, diagnosis, and current therapy. Crit Care Res Pract. 2012;2012:908169. https://doi. org/10.1155/2012/908169

29. Sánchez-Miralles A, Castellanos G, Badenes R, Conejero R Abdominal compartment syndrome and acute intestinal distress syndrome [Article in Spanish]. Med Intensiva. 2013;37(2):99-109. https://doi.org/10.1016/j.medin.2011.11.019

30. Talisman R, Kaplan B, Haik J, Aronov S, Shraga A, Orenstein A. Measuring alterations in intra-abdominal pressure during abdominoplasty as a predictive value for possible postoperative complications. Aesthetic Plast Surg. 2002;26(3):189-92. https://doi. org/10.1007/s00266-001-1469-5

31. Perin LF, Saad R Jr, Stirbulov R, Helene A Jr. Spirometric evaluation in individuals undergoing abdominoplasty. J Plast Reconstr Aesthet Surg. 2008;61(11):1392-4. https://doi.org/10.1016/j.bjps.2008.02.028

32. Rodrigues MA, Nahas FX, Gomes HC, Ferreira LM. Ventilatory function and intra-abdominal pressure in patients who underwent abdominoplasty with plication of the external oblique aponeurosis. Aesthetic Plast Surg. 2013;37(5):993-9. https://doi.org/10.1007/ s00266-013-0158-5

33. Nozawa $E$, Kobayashi $E$, Matsumoto ME, Feltrim MIZ, Carmona MJC, Auler Júnior JOC. Identificação dos fatores de risco que influenciam no desmame de ventilação mecânica em pacientes traqueostomizados após cirurgia cardíaca. Arq Bras Cardiol. 2003:80(3):301-5.

34. Rodrigues AJ, Évora PRB, Vilela V, Vicente W. Postoperative respiratory complications [Article in Portuguese]. Medicina (Ribeirao Preto). 2008:41(4):469-76. https://doi.org/10.11606/issn.2176-7262. v41i4p469-476 